\title{
FORMAS DE CONCEBER A TERRA NO OESTE DO BRASIL
}

\author{
WAYS TO UNDERSTAND THE LAND IN WESTERN BRAZIL
}

\author{
Nataniél Dal Moro* \\ natanieldalmoro@bol.com.br
}

RESUMO: Discute-se como ocorreu a transformação econômica do oeste brasileiro, que era concebido na década de 1920 como "cerrado estéril" e passou a ser pensado, décadas depois, como a "última fronteira agricultável do mundo", enfatizando-se as mudanças alavancadas na segunda metade do século XX pela monocultura da soja nestas plagas, mais especificamente na região sul do então Estado de Mato Grosso Uno.

PALAVRAS-CHAVE: Território; Colonização; Agricultura.

ABSTRACT: This paper discusses how the economic transformation of western Brazil, which was conceived in the 20's as "cerrado esteril" (infertile cerrado) and decades later came to be thought of as the "last frontier of the world's arable land", emphasizing in particular the leveraged changes in the second half of the 20th century by the monoculture of soybean in these plagues, more specifically in the southern region of the then State of Mato Grosso Uno.

KEYWORDS: Territory; Colonization; Agriculture.

INTRODUÇÃO

As terras que atualmente compõem o oeste brasileiro, não

\footnotetext{
* Doutor em História pelo Programa de Estudos Pós-Graduados em História da Pontifícia Universidade Católica de São Paulo e Pós-Doutorando pela Universidade Nova de Lisboa (UNL).
} 
fossem pelo trabalho de apresamento e escravidão de nativos, e também por causa da descoberta de metais preciosos em meados do século XVIII, eram pensadas como uma área com pouco potencial a ser explorado (GOES FILHO, 1999, p. 89-127). A região ficou distante dos olhos da economia ocidental durante séculos. Havia o que se convencionou chamar nos estudos acadêmicos publicados nos anos 1960-70 de inserção marginal ou periférica no capitalismo ocidental, e talvez fosse melhor que assim tivesse ficado, pois a biodiversidade tem sido vítima constante do "progresso" pósavanço da fronteira agrícola e "civilizadora" sobre as terras do oeste brasileiro, como tão bem nos lembraram vários estudiosos, mas notadamente José Graziano da Silva (1982).

No século $X X$, em especial na segunda metade, determinados grupos sociais, particularmente pecuaristas, fazendeiros e gestores de empresas agropecuárias, desencadearam diversos processos, em grande parte com financiamento e/ou apoio expressivo do Estado brasileiro, e que transformaram literalmente muitas porções de terras até então não incluídas no mundo do capital. O oeste, território - aqui pensado como uma porção de terra na qual viviam diversos sujeitos - que não se pode precisar com exatidão o lugar de seu início ou término passou a ser um espaço disputado e valorizado economicamente: tornou-se "a última fronteira agricultável do globo", algo bem diferente do ocorrido décadas atrás, quando a região era vista com severas restrições, sobretudo quando o assunto versava a respeito da densidade populacional e da agricultura. ${ }^{1}$

OESTE: TERRITÓRIO AFASTADO E DESCONHECIDO, LUGAR DE NINGUÉM

Ainda hoje, século XXI, o Brasil é desconhecido para muitos dos que o habitam. O leste brasileiro historicamente sempre teve os melhores meios de comunicação e de transporte. No oeste, por sua vez, a situação foi bem outra. Essa região, também conhecida e retratada em algumas obras como Fronteira Oeste, Rincões do Brasil, Grande Estado do Brasil Central, 
Confins da Nação, Hinterlândia Brasileira, Grande Estado do Oeste Brasileiro, Sibéria Brasileira, Brasil Central, dentre outras denominações não menos emblemáticas, foi vista politicamente como um local que precisava urgentemente ser protegida, ocupada, povoada e colonizada por "elementos nacionais", e não obstante produzir mercadorias dentro dos ditames da sociedade "civilizada". ${ }^{2}$ Seria preciso, conforme estudos já citados, guarnecer as fronteiras, além de plantar e colher alimentos nestas terras, gerando divisas para o Brasil. Porém, poucas pessoas abraçaram tais empreitadas, pelo menos não com a mesma força do que os discursos e os projetos propunham.

Desde a época colonial, quando se deu a construção de fortes e presídios para proteger as fronteiras das investidas espanholas, como o Forte Coimbra (1775), no que é o atual território do Município de Corumbá e presídios em Ladário, Miranda e Corumbá, cidades que hoje integram uma parte do pantanal sul-mato-grossense, até em tempo mais recente, década de 1850, época da implantação de colônias militares (entenda-se povoações) na região, tais como a de Nioac (1855), de Dourados (1862), Núcleo Colonial do Taquari (1862, na cidade de Coxim), de Miranda e de Bela Vista, o oeste brasileiro era visto como uma imensa área territorial que necessitava de proteção, pois aparecia como território da Coroa Portuguesa muito mais na cartografia do que de fato o era.

Especificamente no caso do território que hoje integra o Estado de Mato Grosso do Sul (MS), as preocupações estatais para com esta área sempre foram muitas, porém a ação era aquém das projeções discursivas. Os projetos acabaram por alterar pequenas parcelas do mundo oestino. A literatura histórica registra essas terras como "espaços vazios" que tinham que ser ocupados por "elementos nacionais" a fim de afastar a presença de estrangeiros da região, entretanto, esta área carecia enormemente de meios de comunicação com o leste brasileiro. A afirmação do Dr. Antônio Joaquim Ribas, que data de 1856, sintetiza com propriedade algumas destas limitações. Para este político, a abertura de uma 
[...] vasta estrada fluvial do Paraná, parece Ihe haver fadado a mais enérgica e benéfica influência sobre a sorte das populações do sul do Império. É por ela que se deve fazer a permutação de produtos e de idéias entre uma parte importante das províncias de Minas Gerais, Goiás, Mato Grosso, São Paulo, Paraná, Rio Grande do Sul e as Repúblicas do Paraguai, Argentina e do Uruguai; é por ela e por seus afluentes que a população e a indústria se difundirão por essas amplas e férteis regiões, hoje em grande parte ermas, e que a riqueza e a civilização irão aquecer, iluminar e fazer medrar as povoações que aí vegetam enfezadas pela quase segregação da sociedade humana (BARROS, 1950, p. 13-14).

Como se pode observar, em meados do século XIX o oeste brasileiro foi pensado por alguns sujeitos como uma região distante do Brasil litorâneo que devia, sem demora, ser aproximada do restante da nação e servir como um elo entre aquele Brasil e as nações vizinhas. Portanto, nesse período, década de 1850, a presença de não-brasileiros em áreas fronteiriças ao Brasil não era vista propriamente como um problema. Décadas depois, essa concepção foi alterada.

A Guerra do Paraguai (1864-70) reavivou na mentalidade nacional algumas das preocupações existentes no século XVIII sobre o oeste brasileiro, e que na primeira metade dos anos oitocentos esmaeceram-se diante de outros interesses, em particular o comercial, quando se passou a incentivar o comércio entre os países recém-independentes. Findado o conflito, sobressaíram-se as concepções que propagavam a região como um território litigioso que deveria ser ocupado efetivamente pelo Estado brasileiro o quanto mais fosse possível, não podendo permanecer na situação em que estava inabitado de elementos nacionais.

Essa tarefa de propagandear que o local em pauta estava "inabitado" foi realizada com o regresso dos soldados para as suas províncias. Os combatentes divulgaram a notícia de que no sul de Mato Grosso existiam terras ainda não ocupadas pelo homem branco. Propagouse também a informação de que grande parte das terras oestinas não tinha dono. Isso contribuiu decisivamente para a vinda de migrantes de todos os 
locais do Brasil, mas em particular do Rio Grande do Sul e de Minas Gerais. Foi a partir da década de 1870 que boa parte dessas terras, consideradas litigiosas até 1872, quando ocorreu a assinatura do Tratado de Paz LoizagaCotegipe, foram ocupadas por nacionais. ${ }^{3}$

Bastava chegar e ocupar as terras. Muitas famílias afazendaram-se de imensas áreas, geralmente as próximas de cabeceiras e leitos de rios perenes. ${ }^{4}$ Formaram-se então as grandes propriedades rurais, algumas delas com mais de 500 mil hectares, em geral concedidos pelo poder público aos que solicitassem os títulos destas áreas devolutas. ${ }^{5} \mathrm{~A}$ produção calcou-se basicamente na erva-mate e, mais ainda, na pecuária extensiva. Contudo, tais atividades não conseguiram adensar o número de habitantes nestes "espaços vazios" e nem mesmo reverter a ideia difundida sobre a qualidade das terras, concebidas como pouco produtivas à agricultura daqueles tempos. ${ }^{6}$

Um viajante que esteve na região sul de Mato Grosso na década de 1920 relatou que o lugar era desconhecido do restante do país ao ponto de os brasileiros conhecerem menos o Estado de Mato Grosso "do que os europeus ao Brasil." (AMARAL, 1927, p. 11). Essa afirmação, e que foi feita por Luiz Amaral, sinaliza apropriadamente o quão distante estavam as terras oestinas do Brasil litorâneo nos anos 20. Ademais, havia a predominância na sociedade de outra ideia sobre o oeste. Difundiu-se um pensamento de que estas terras só produziam mato, e nada mais do que isso. Portanto, não seriam adequadas à agricultura. Ademais, corria-se inclusive o risco de ser, literalmente, devorado por determinados animais. ${ }^{7}$

Levando-se em consideração estas situações, quem iria para este lugar com o intuito de povoá-lo, colonizá-lo ou torná-lo produtivo? E, mais, quais trabalhos fariam nestas terras? Por causa desses fatores mencionados, a região permaneceu durante a primeira metade do século $X X$, quando comparada com outros territórios brasileiros, assim sinalizaram alguns autores, entre os quais podemos incluir o nome de Frederico Rondon (1934), como parcamente povoada. Já as suas terras, eram vistas como inadequadas à agricultura, em particular as áreas de cerrado, que 
concentravam, naquele momento, sobretudo criações extensivas de bovinos.

A COLONIZAÇÃO NECESSÁRIA SOBRE UMA TERRA ESTÉRIL

Não havia unanimidade nos diálogos e nas afirmações de autoridades públicas e privadas quando o assunto era povoamento, ocupação ou colonização do oeste brasileiro. Um escritor do início do século XX pensou a imigração européia como positiva para Mato Grosso. No entender de Marques (1923, p. 77), as cidades de Três Lagoas, de Campo Grande e de Aquidauana, dentre outras, ofereciam à colonização européia "todos os elementos de progresso" que ela carecia para a sua estruturação, uma vez que o comércio local dependia, lamentou o autor, "ainda exclusivamente do gado, única indústria dessa região."

A atividade pecuária a que se referiu Marques (1923) - seja ela nas suas ramificações pastoril, comercial ou industrial - não conseguiu adensar o número de habitantes em Mato Grosso. Embora a região sul do Estado (área que corresponde ao atual Estado de Mato Grosso do Sul) tivesse nos anos 20 imigrantes japoneses, holandeses, portugueses, italianos, sírios, e de muitas outras nacionalidades, a densidade populacional desta área era a menor dentre todos os Estados do Brasil, fato que perdurava há décadas. No ano de 1920, o Estado tinha 250 mil habitantes e a densidade demográfica era de 0,17 habitantes por $\mathrm{km}^{2}$. Esse número, quando confrontado com as densidades existentes nas demais unidades federativas do país, ficava na última colocação.

Portanto, para algumas autoridades, havia dois imensos problemas neste território: escasso povoamento e quase que nenhuma utilização do solo para plantio agrícola. Visando solucionar parte desta questão, determinados sujeitos defenderam a utilização de pessoas de origem asiática para colonizar tais plagas. Houve também os que incentivaram a vinda de indivíduos europeus e, ainda, os que disseram que 
o Brasil, na década de 1930, já não precisava mais de imigrantes para povoar o território oestino. Para estes, bastava realizar migração de gente do leste para o oeste do país, tese que foi largamente defendida por Frederico Rondon (1934) na obra intitulada Pelo Brasil Central.

Alguns autores, por sua vez, foram mais específicos nas suas análises. E esse foi o caso da produção textual de Luiz Amaral (1927, p. 1112), que considerou a imigração japonesa em Campo Grande como muito benéfica à região como um todo. Segundo ele, a colônia japonesa radicada no local, e constituída de dois mil integrantes, era muito "grande" e as suas realizações mostravam "bem claramente" que não havia "outro elemento tão apropriado ao progresso de Mato Grosso."

O trabalho desenvolvidos pelos nipônicos em áreas rurais de Campo Grande, assegurou Amaral (1927, p. 12), derrubava os argumentos até então endereçados a eles, já que alguns sujeitos, e que proferiam opiniões mais radicais, os viam como indivíduos que não se adaptavam "completamente ao meio brasileiro", nem à religião e à estrutura física do lugar. Para Amaral, nada disso procedia. Outro fator que também engrandecia a presença dos japoneses em Mato Grosso era o das suas proles. Os nascidos na região, externou Amaral (1927, p. 12), seriam "autênticos caboclos brasileiros, em tudo." Ademais, os nipônicos mostravam-se os trabalhadores mais ordeiros daquele lugar. O trabalho ordeiro, por sua vez, foi a característica que mais chamou a atenção de Amaral, pois em razão deste fator os japoneses tinham transformado as terras oestinas.

Antes da presença de tal "elemento ordeiro" neste território, parte considerável das terras foi pensada como inadequada à agricultura. Os japoneses, no entanto, demonstraram que essas terras eram muito produtivas e propícias à prática agrícola. Os trabalhos destes sujeitos ordeiros derrubaram a "crença geral", afirmou Amaral (1927, p. 12), que propagava o solo oestino como terras que só produziam "capim" e eram estéreis, servindo apenas, "quando muito, para a criação de gado comum."

Os nipônicos foram responsáveis, considerou o autor, por 
trabalhar de modo mais sério as terras do cerrado brasileiro, algo que até então ninguém teria feito com tanto afinco. Através deste labor, eles provaram que todas as demais terras de cerrado, às vezes chamadas inclusive de deserto, também podiam ser úteis para os trabalhos agrícolas. O labor destes imigrantes sobre as terras do "cerrado estéril" demonstrou, conforme palavras de Amaral (1927, p. 13-14), que esta área estava "apenas esperando" que fosse iniciada uma "política inteligente de imigração" para tocá-la com a "vara mágica do trabalho, para que se desfaça em abastança." Devido à presença destes imigrantes asiáticos, Amaral já não temia "pelo futuro do Brasil", uma vez "que no Brasil", para ele, estava "o próprio futuro do mundo!"

Esse trabalho com a terra, e a consequente produção de alimentos pelos japoneses, foi vista como uma qualidade altamente positiva à região, pois essas áreas não possuíam nenhuma atividade de destaque no campo agrícola. Quando muito, criavam-se bovinos via pecuária extensiva. Logo, o fato era realmente notável. Contudo, alguns escritores do período, como é o caso de Mario Lima Beck (1935), foram mais criteriosos quando o assunto versou sobre a atribuição de adjetivos positivos aos que colonizaram, ou queriam colonizar, a região sul de Mato Grosso. Para este autor, havia colonizações estimuláveis e outras que deviam ser brecadas.

A obra Nova querencia. Chronica das emigrações riograndenses para Matto Grosso, de Beck (1935), exemplifica muito bem como alguns sujeitos pensaram a presença de determinados colonizadores em terras oestinas. Nesse texto, o autor relatou a epopéia dos sul-riograndenses que migraram para o sul de Mato Grosso e mostrou-se preocupado com o abandono no qual estavam as terras do oeste do Brasil no final do século XIX e nas primeiras décadas do XX. Nessa época, a estimativa era de que 10 mil gaúchos moravam no sul de Mato Grosso, sendo que a maior parte emigrou do Rio Grande do Sul devido questões políticas relacionadas com a Revolução Federalista (1893-95).

Depois de elencar as causas que motivaram a saída de gaúchos 
para a região citada e contestar que a mesma era espontânea e devido a questões econômicas, o autor quantificou em 50 mil os gaúchos e seus familiares residindo na região em 1935, por ele chamada de Território de Maracaju ou Pampa Mato-Grossense. Para Beck (1935, p. 42 e 58), Mato Grosso era "a maior reversa do Brasil" e, dentre todos os estados do país, era o que mais necessitava de imigrantes para ocupá-lo, já que tinha uma "imensa área despovoada", cujas terras eram "fertilíssimas." Em específico, externou o escritor, o território do sul de Mato Grosso era a "zona mais próspera" e na qual havia o maior contingente populacional em relação à porção norte de Mato Grosso (BECK, 1935, p. 58).

Isso se devia majoritariamente por causa da migração gaúcha para estas terras. Os sul-rio-grandenses tinham ocupado vastas áreas de campo do planalto mato-grossense, chegando até o Pantanal, que não tinha solo tão apropriado para o cultivo agrícola. Fixaram-se também, assegurou Beck (1935, p. 43), "nas zonas periféricas da fronteira com o Paraguai, reafirmando assim, a gloriosa tradição de sentinelas da pátria." Como o título da obra do escritor bem ilustra, os gaúchos fizeram do sul de Mato Grosso uma "nova querência", ou seja, uma nova casa para eles e os seus familiares. Este tipo de migrante era aceitável para a região e devia ser visto, conforme afirmou o autor, como um grande aliado da nação brasileira na defesa da nacionalidade, em particular no quesito território, pois trabalhavam efetivamente com a terra e dela tiravam o próprio sustento, algo que nem todos os sujeitos, mas em particular determinados imigrantes, faziam ao adentrar em território nacional.

Portanto, segundo Beck (1935, p. 43), havia imigrações que não deviam, de forma alguma, ser estimuladas pelo poder público para ocupar os solos oestinos, já que os seus integrantes não trabalhavam a terra, logo, não tinham utilidade para defender a nação brasileira, pois não revertiam a situação da inexpressiva densidade populacional de uma "imensa área despovoada" que fazia fronteira, inclusive seca, com nações como a Bolívia e o Paraguai.

Beck advertiu de modo taxativo os leitores que nem sempre a 
presença de imigrantes num local representava, necessariamente, a colonização desta área. No seu entender, alguns sujeitos "imigravam em grande número", porém não tinham "sentimento colonizador" ao chegarem em novas terras. Neste padrão, encontravam-se os ciganos, os turcos e os sírios. Os primeiros foram considerados "nômades" e qualificados como "vagabundos" pelo escritor, já que viviam "vendendo tachos de cobre" e obtendo dinheiro fácil pela realização desta atividade. Os demais também não eram aceitáveis, pois sempre estavam percorrendo as vias de comunicação para mascatear bugigangas. Nas cidades e vilas, erguiam mercadinhos, também com o objetivo de obter dinheiro fácil.

Os "judeus e todos os povos de origem semita", no entender de Beck (1935, p. 41), também pertenciam "a essa espécie de imigrantes." Eram, todos eles, "gananciosos aproveitadores de todas as intermediações. Nenhum deles, para a terra, para a lavoura, para o heróico desbravamento das colonizações civilizadoras e progressistas" tinha utilidade. Na opinião de Beck (1935, p. 41), definitivamente esses sujeitos não serviriam para a proteção do território nacional da mesma forma que os migrantes e os imigrantes que trabalhavam efetivamente com a terra, produzindo alimentos e fixando residência no local com os seus familiares. Para um país como o Brasil, não eram "essas, certamente, as imigrações estimuláveis." (BECK, 1935, p. 41).

Sendo assim era justificável, no entender de Beck (1935, p. 41), "por tais e outras razões de ordem moral e biológica" que os governos estabelecessem restrições para estas correntes imigratórias que adentravam no território brasileiro. Devia-se controlar, e até impedir, a entrada de alguns sujeitos que foram intitulados de "indesejáveis". Neste rol, foram incluídos os aventureiros, os jogadores profissionais, os malfeitores, as prostitutas e os criminosos. E Beck (1935, p. 41-42) advertiu, outra vez, sobre o perigo da presença deste tipo de colonizadores no oeste brasileiro. Para ele, a experiência obtida no passado já tinha mostrado às nações sobre "a inadmissibilidade da livre imigração." A política brasileira devia, então, primar por defender os braços que rasgavam, semeavam e 
valorizavam o solo. Estes sim mereceriam toda a simpatia e o apoio das autoridades, pois trabalhavam "a natureza e não as realizações do trabalho alheio, fecundando-a, descobrindo-lhe utilidades", e não podiam "ser recebidos com prevenções." (BECK, 1935, p. 42).

Além disso, esse tipo de colonizador edificava, através das suas atividades, um "labor honesto" que não colocava "em perigo a integridade nacional." Para Beck (1935, p. 43), o que constituía "um grave mal à nacionalidade" e devia ser solucionado em curto espaço de tempo para que a nação brasileira não perecesse diante de outras culturas, em particular as existentes no Paraguai, era a falta de escolas brasileiras nas áreas lindeiras do sul de Mato Grosso. Essa chamada de "atenção" do autor indicou também outro grave problema que perdurava nas terras oestinas.

Para Beck (1935, p. 43), a colonização desta imensa área - hoje grande parte do território do Estado de Mato Grosso do Sul - era realizada, e continuava sendo feita nos anos 30, sem o apoio do poder público. Por vezes, e o escritor fez esta afirmação com o intuito de questionar as ações das autoridades públicas sediadas em Cuiabá que se posicionavam contrárias à migração gaúcha, o poder constituído chegou a dificultar o processo colonizador que ocorria no sul do então Estado de Mato Grosso Uno. ${ }^{8}$ Em razão disso, devia-se considerar a colonização ocorrida nestas plagas como uma obra feita "a custa de iniciativas privadas". A colonização era fruto do labor de "abnegados colonizadores" que, ao empreenderem tal atividade, "balizaram domínios brasileiros, traçaram caminhos, abriram florestas, povoaram campos, plantaram, fundaram vilas e cidades." Portanto, a "colonização do sul", na análise de Beck, "foi obra exclusiva dos imigrantes." (BECK, 1935, p. 43).

Na década de 1940, os escritores que se detiveram na questão do povoamento das terras oestinas apontaram outros fatores para a permanência desta realidade. No entender de Archimedes Lima (1941, p. 108), o poder público atuava no sentido de fixar colonos em áreas agricultáveis, porém, as tentativas feitas até aquele momento "redundaram em ruidosos fracassos" e o resultado mais nítido disso era que estas terras, 
por ele chamadas de "Oeste abandonado", continuavam despovoadas. Para Lima (1941, p. 111), a região seria colonizada com sucesso no momento que se construíssem estradas para viabilizar o escoamento da produção agrícola, situação que estava sendo projetada nessa época - ano de 1941 pois o então Presidente Getulio Dornelles Vargas tinha decretado leis que destinavam verbas da União para instalar colônias agrícolas, fazer colégios para os filhos dos agricultores e construir e conservar estradas, dentre outras benfeitorias.

A grande aposta de Lima (1941, p. 111) era que com a colonização ocorreria um aumento do número de pessoas na região e, com este, ter-se-ia então "o engrandecimento do Estado. Do mais alto alcance", segundo ele, era, "portanto, o decreto com que o Sr. Getulio Vargas nos presenteou, a nós deste Oeste abandonado. Para nós é mesmo a lei de colonização nacional a mais sábia das leis de Getulio Vargas." (LIMA, 1941, p. 111). ${ }^{9}$ Frederico Rondon (1947, p. 1340), já no final da década de 1940, também concebeu as terras oestinas como pouco povoadas e desconhecidas do restante do Brasil. A permanência desta condição, para ele, era "grave" e o país não podia "manter por muito tempo ainda a ignorância de tão vastas zonas da Terra."

Os autores mencionados até então atribuíram o que por eles foi concebido como o parco povoamento de Mato Grosso a questões variadas, contudo, nenhum deles enveredou suas análises para a estrutura econômica presente nestas terras. Nesse sentido, as reflexões propostas por Nelson Werneck Sodré no início dos anos 40 são emblemáticas pela forma como tal realidade foi questionada e pelo teor dos argumentos expostos por este autor, que era militar e serviu na cidade de Campo Grande na década de 1930.

Sodré (1941, p. 126-127), por sua vez, também pensou o oeste como um lugar com pequena densidade populacional. Para ele, estas terras eram um "desertão" humano e material no qual predominaria um tipo específico de sociedade: a pastoril. Essa estrutura social, que trabalhava essencialmente com a pecuária desde meados do século XIX, foi vista pelo 
militar como maléfica para o desenvolvimento do Estado de Mato Grosso e das demais terras oestinas. Os seus escritos indicam que as cidades do Grande Estado do Brasil Central, assim como as de outras áreas da sociedade pastoril, tiveram, por causa da existência desta forma de sociedade, um desenvolvimento muito aquém do possível. ${ }^{10}$

A cultura pastoril, segundo externou Sodré (1941, p. 167-168), impediu a formação de outras atividades agrárias, como a lavoura de alimentos, tão fundamental à fixação de sujeitos na terra e o consequente adensamento demográfico. Em decorrência do não desenvolvimento da agricultura houve dificuldade do homem se fixar na região, produzir e comercializar alimentos, enfim, gerar riqueza a partir do trabalho com e na terra, pois a sociedade pastoril ocupava todos os espaços territoriais para a criação extensiva de animais, notadamente bovinos. ${ }^{11}$

As atividades realizadas em algumas fazendas, constatou Almeida (1944, p. 74), que estava em viagem de estudos à região sul de Mato Grosso nos anos 40, centravam-se quase que exclusivamente em lides com o gado, e nada mais segundo esse escritor. Com certo espanto, o autor relatou aos seus leitores do Boletim da Associação dos Geógrafos Brasileiros que as fazendas da Serra de Maracaju não possuíam atividades agrícolas que suprissem, nem minimamente, as demandas locais. Nessa região, ao contrário das demais propriedades rurais do restante do Brasil Central, não havia sequer "uma certa auto-subsistência." Mesmo com as "relativas dificuldades de transporte", assegurou Almeida (1944, p. 74), as fazendas desta área importavam "quase tudo o que" consumiam.

Diante dessa realidade que insistia em se fazer presente nas terras oestinas, e já incomodava algumas autoridades desde o último quartel do século XIX, os poderes públicos, sobretudo em âmbito regional e local, atuaram em vários períodos e de diversos modos.

UMA COLONIZAÇÃO ECONÔMICA: VENDA DE TERRAS E MONOCULTURAS AGRÍCOLAS 
Recorrendo a notas do passado, vê-se que o poder público, seja ele das esferas federal, estadual ou municipal, atuou destacadamente nas terras do oeste brasileiro com o intuito de fixar pessoas nesse território. Há registros de leis, decretos, projetos, discursos e obras em todas as décadas do final dos anos oitocentos até meados do século XX. Essa constância de ações por parte de inúmeras autoridades, mesmo que em muitos casos os projetos não tenham sido materializados, demonstra um interesse de determinadas autoridades e grupos privados em solucionar uma questão que era vista como problema: o fato das terras não serem ocupadas populacionalmente e nem produzirem divisas para o Brasil.

Visando eliminar definitivamente essa realidade existente há décadas no Estado de Mato Grosso, as autoridades estaduais venderam, sobretudo no primeiro lustro da década de 1950, imensas áreas de terra para companhias privadas de colonização. Os registros aquilatam que mais de 20 empresas compraram grandes áreas de terras devolutas, em particular do poder público estadual, e, depois, fracionaram estas áreas em lotes que, posteriormente, foram vendidos para terceiros (MORO, 2007). Segundo Campos (1955, p. 94), no governo de Fernando Corrêa da Costa celebraram-se 19 contratos deste tipo. Essa política de colonização, hoje bastante questionada pela historiografia regional, foi responsável pela fragmentação de algumas das mais extensas áreas territoriais do oeste brasileiro, tanto nas porções sul como norte de Mato Grosso, já que existiam propriedades com mais de quinhentos mil hectares.

Devido a essa política houve uma intensa migração de pessoas do leste do país para terras do Estado de Mato Grosso, à época também conhecido como o "Grande Estado do Brasil Central". Buscando terras por preços mais baixos, milhares de migrantes rumaram para Mato Grosso com o intuito de comprar lotes vendidos pelas companhias de colonização, ou de outros proprietários. No decorrer das décadas de 1950 até o ano de 1980, especificamente a porção sul de Mato Grosso, que depois de 1977 constituiu o Estado de Mato Grosso do Sul, recebeu mais de $500 \mathrm{mil}$ migrantes, em especial dos Estados de São Paulo, Paraná, Minas Gerais, 
Goiás e Rio Grande do Sul (MORO, 2007, p. 109). Nesse processo, vieram migrantes com as mais diversas culturas, modos de vida e de trabalho e, às vezes, não foram muito bem recebidos nas terras para as quais rumaram.

Um exemplo marcante seria a migração expressiva de nordestinos para Mato Grosso, já que parte deles não tinha interesse inicial no trabalho com a terra, mas sim nas áreas urbanas. Grande parte deles saiu da Região Nordeste com destino ao Estado de São Paulo. Chegando na metrópole paulista, nem todos conseguiam colocação no mercado de trabalho. A solução que lhes restou foi migrar mais uma vez, só que agora para terras oestinas. Por vezes, a própria Secretaria de Assistência Social da capital paulista fretou ônibus e/ou custeou as passagens para o deslocamento destes migrantes. Geralmente, o destino final dos veículos era a região central das maiores cidades de Mato Grosso, que à época eram as urbes de Cuiabá, Dourados, Rondonópolis, Corumbá, Ponta Porã e, sobretudo, Campo Grande. ${ }^{12}$

Um outro exemplo de migração, no entanto concebida pelas autoridades mato-grossenses com bons olhos, foi a dos sujeitos que trabalhavam com a terra, em particular os trabalhadores rurais de algumas culturas agrícolas. Esse foi o caso de parte dos migrantes sulistas que rumaram para a região sul de Mato Grosso no final da década de 1960 e nos anos 70, em particular pelo valor das terras. Com o dinheiro da venda de um hectare no Rio Grande do Sul era possível comprar, dependendo do local, de seis até dez hectares "no Mato Grosso", como genericamente era chamada a região que ficava após o rio Paraná. Muitos dos migrantes adquiriram terras nas regiões conhecidas como Grande Dourados ou Campos da Vacaria. A atividade econômica desenvolvida calcou-se sobremaneira no plantio de grãos, em particular no milho e na soja. E foi devido à existência dessas culturas que houve, em grande parte, modificações fundamentais nas terras oestinas do Brasil, inclusive com o tão desejado adensamento populacional. A cultura da soja, em específico, literalmente transformou o campo e as cidades mato-grossenses (MORO, 2012, p. 1-14). 
SOJA, ANTES DE TUDO, UM ALIMENTO PARA OS ANIMAIS

Na década de 1950, a pecuária extensiva continuava a ser a atividade econômica que predominava no sul de Mato Grosso. Considerável também era a agricultura que praticamente não utilizava maquinários ou adubos e possuía pequena variação das culturas de grãos, sendo por vezes chamada em certos materiais de agricultura primitiva. Esta se caracterizava pelo plantio de milho, mandioca, arroz, aveia, café e algodão, mas nada expressivo do ponto de vista econômico (COMISSÃO..., 1955, p. 52-53). Nessa época, anos 50 , não consta em nenhum material que havia plantio de soja na região. No período em estudo, esse grão era pouco conhecido no Brasil, contudo, os registros de entrada da soja no país datam do final do século XIX e a primeira colheita foi realizada em 1914 no Município de Santa Rosa, no Estado do Rio Grande do Sul (SCHLESINGER, 2010). ${ }^{13}$

Nos Estados Unidos da América (EUA), o grão da soja também não era muito popular, entretanto, este país produzia em 1959 "mais de $60 \%$ da soja" mundial, embora não consumisse na totalidade a produção. Dentre os países que compravam a soja norte-americana estavam a Inglaterra e o Japão. Esta primeira introduziu o grão na constituição dos alimentos, como a salsicha, durante a Segunda Guerra Mundial (1939-45). O azeite de oliva também passou a ter uma versão que contava com determinada porcentagem de óleo de soja (AMARAL, 1959, p. 55).

No artigo intitulado Soja - instrumento do imperialismo, Pompêo do Amaral (1959) se encarregou de apresentar este grão - no caso a soja - como maléfico para a sociedade brasileira. ${ }^{14} \mathrm{O}$ alimento seria prejudicial por várias razões: tinha baixa quantidade de fósforo e cálcio, era pouco apetitoso e possuía a fasina, que é uma proteína tóxica e também soponinas "que destroem os glóbulos vermelhos do sangue". A farinha de soja cheirava urina e tinha gosto instável que lembra tinta e grama, ademais causava "moléstias circulatórias" e era alimento que se dava para os animais. Segundo Amaral, a soja só era muito consumida nos EUA pelo 
fato da população desconhecer o mal que ela acarretava à saúde, tanto é que o consumo era atrelado a outros produtos mediante parcial hidrogenação. A margarina seria, segundo escreveu Amaral (1959, p. 55), um exemplo clássico.

Em 1955, os EUA já produziam 5,5 quilos de soja para cada pessoa do globo e consumiam apenas $3 / 5$ desta produção. $O$ restante precisava ser vendido, porém, o entendimento social que predominava dizia que a soja era um alimento "impalatável" e que se destinava ao gado e às aves, e não às pessoas. A questão foi resolvida aos poucos através de propagandas que difundiram outra concepção sobre a soja e procuraram ressaltar os benefícios do alimento (AMARAL, 1959, p. 42-58).

Embora desde 1920 já existisse um grupo empresarial estruturado nos EUA, foi nos anos 50, de acordo com Amaral (1959, p. 55), que a "prospecção e vulgarização" do grão se tornou o ponto-central da American Soybean Association, que era uma "influentíssima organização". Revistas, folhetos, pequenos filmes e anúncios veiculados nos meios de comunicação, como a TV, passaram a divulgar as contribuições científicas que a soja traria se consumida. Demonstrações ao vivo também ocorriam: "Já com o fito de familiarizar os espanhóis com o seu óleo de soja, os Estados Unidos fizeram, aos visitantes da recente feira de Barcelona, larga distribuição de batatas fritas, aos olhos do público, com óleo de soja." (AMARAL, 1959, p. 55). Degustação de "pães mistos de soja" e de "pedaços de frango fritos em óleo de soja" eram outras formas de chamar a atenção para o produto, até então desdenhado pelos consumidores europeus (AMARAL, 1959, p. 55).

No oeste brasileiro a soja começou a ser plantada no final da década de 1960. As primeiras colheitas foram desastrosas do ponto de vista da produtividade. Em meados dos anos 70, depois de órgãos de pesquisa como a Empresa Brasileira de Pesquisa Agropecuária (EMBRAPA) - terem aprimorado os grãos desta oleaginosa e os agricultores (por vezes chamados de sojicultores) já terem mais experiência na lida com a terra, obtiveram-se bons resultados na lavoura. A ajuda do poder público para 
financiar implementos, maquinários, adubos, fertilizantes e defensivos agrícolas em geral, e equipar a região com silos, armazéns e estradas para a chegada de produtos e o escoamento da produção não foi inexpressiva: coube ao Governo Federal a maior tarefa e o II Plano Nacional de Desenvolvimento, vigente entre 1975-79, foi criado justamente para viabilizar a transformação do cerrado brasileiro em terras agricultáveis para o grão da soja, assunto já problematizado por inúmeros estudiosos há décadas, tal como podemos observar em obra de Graziano (1982).

Pode-se dizer que na década de 1970 começa-se a ocupar efetivamente via agricultura monocultora os cerrados "do Mato Grosso". Os dados quantitativos que se têm sobre o plantio e colheita da soja na década de 1970 são muito acanhados em relação às informações existentes da década de 1980 até o ano de 2010. Isso sinaliza o quanto este grão ainda era desconhecido da sociedade brasileira no início do período em pauta, bem como as pesquisas eram recentes em relação à soja e ao solo mais apropriado para o plantio desse grão no Brasil. Mais uma vez é preciso lembrar que o generoso apoio do poder público federal foi imprescindível para a materialização da monocultura da soja, e também da do milho, bem como da pecuária, sobretudo a bovina. Não fosse via verbas da União, muitas delas obtidas por meio de empréstimos internacionais com juros nada convidativos, as terras do Brasil Central não teriam sido ocupadas da forma como o foram.

Em 1977, a agropecuária brasileira cresceu 9,6\%. Na década de 1970 havia altos e baixos da produção que eram provocados em grande parte pelas condições climáticas e pelo precário acesso às tecnologias agrícolas. A produção de soja de 1978 foi, por causa da questão climática, $23,8 \%$ menor do que a do ano anterior. Na segunda metade do século XX a soja foi se alastrando pelo território nacional. Em 1960, os Estados da Região Sul do Brasil - Paraná, Santa Catarina e Rio Grande do Sul produziram $98 \%$ da soja brasileira. No final desta década, as regiões Sudeste e Sul responderam por $80 \%$ dos grãos de soja do Brasil. No ano de 1990 a produção de soja já era $130 \%$ maior do que aquela registrada no ano 
de 1980 .

A Região Centro-Oeste não chegou a produzir $2 \%$ da soja brasileira nos anos 70. Porém, nas décadas seguintes a situação foi alterada: em 1980, a região, que pode perfeitamente ser chamada também de oeste brasileiro, foi responsável por $20 \%$ da produção nacional. $\mathrm{Na}$ década de 1990 produziu-se na Região Centro-Oeste mais de $40 \%$ da soja brasileira, e no ano de 2003 estas terras, que nos anos 20 foram chamadas de estéreis por algumas pessoas, como bem nos lembrou Amaral (1927, p. 13-14), produziram quase $60 \%$ da soja brasileira (EMBRAPA, 2010). No Estado de Mato Grosso, o aumento foi mais expressivo no início do processo: em 1971 produziu-se menos de 20 mil toneladas; já em 1973 a colheita de soja aumentou para 100 mil toneladas. Houve, no respectivo período, um crescimento de 500\% (EMBRAPA, 2010).

Empreendendo uma análise de conjuntura é possível afirmar que a soja mudou o campo e as cidades oestinas. Indústrias de grande porte que trabalhavam com o grão, como a Bunge, a Cargill e a Sadia, dentre outras, transformaram pequenos lugarejos em áreas valorizadas. Em determinados lugares a soja desbancou a predominância secular da economia bovina. Formou-se também uma outra elite. Os sojicultores passaram a interferir na economia e na política das cidades, alterando o poder das sociedades tradicionais, nesse caso a pastoril (MORO, 2012, p. 114).

Há fronteiras agrícolas que produzem soja nos Estados da Bahia, do Piauí, do sul do Pará, do Maranhão e em países vizinhos ao Brasil, como o Paraguai e a Bolívia. No caso da cidade de Balsas, no Maranhão, a população crescia 20\% ao ano em 2005 devido a ampliação da fronteira agrícola da soja na região. O processo de alargamento desta fronteira e adensamento populacional foi verificado nos anos 70 na região sul e central de Mato Grosso e, nos anos 80, ocorreu no norte do Estado. Na década de 1990 intensificou-se a plantação de soja no sul do Pará e nos Estados da Região Nordeste (MORO, 2012, p. 1-14).

Em curto período de tempo, o Brasil se tornou um dos maiores 
produtores de soja do mundo e a balança comercial brasileira passou a depender, cada vez mais, dos produtos do campo. Embora tenhamos uma produção industrial diversificada, grandes zonas de mineração, é ainda a soja o principal produto da balança comercial. Em 2004, mais de $70 \%$ da soja brasileira, cuja safra foi de aproximadamente 50 milhões de toneladas, teve como destino os mercados externos. Os maiores compradores eram a União Européia (UE) e a China (SCHLESINGER, 2010). Quando a agricultura apresentou resultados pouco satisfatórios para os interesses do capital, como no ano de 2006, a economia brasileira logo foi alterada, em especial no setor dos juros. $O$ mesmo ocorreu no campo da pecuária e da avicultura.

Em 2008, o Brasil era líder mundial na exportação das culturas do café, do suco de laranja, açúcar, álcool, carnes de gado e de frango. No caso da soja e do milho, o país estava em segundo lugar. Os EUA possuíam o primeiro lugar no ranking da soja e mantinham-se igualmente na liderança das exportações de alimentos. Este país, em 2008, vendeu o equivalente a US\$ 140 bilhões, contudo, esta e muitas outras nações, em especial as européias, não possuíam mais fronteiras agricultáveis para ocupar. No mesmo ano a UE vendeu US\$ 128 bilhões.

No caso do Brasil, como demonstramos anteriormente, a questão era outra. Havia vários milhões de hectares que ainda podiam ser ocupados, reocupados (no caso de terras da pecuária extensiva) e a produtividade seguramente também tinha como ser elevada em muitas regiões, fato que dependia de melhorias tecnológicas, grande parte já existentes, mas ainda não acessíveis. Além disso, no Brasil era possível realizar duas safras em cada ano. Primeiro plantando soja e, logo em seguida, milho. Em 2009, o Brasil recebeu US\$ 4,2 bilhões de dólares com a venda de carne bovina, US\$ 5,8 com a de frango e US\$ 17,2 bilhões com o complexo soja, que engloba grão, farelo e óleo.

CONSIDERAÇÕES FINAIS 
Diante destes números, o Brasil era, no início do século XXI, uma das maiores potências agrícolas e agricultáveis do mundo. Em 1960, o país foi um dos maiores importadores mundiais de alimentos, sendo que em 2010 apresentou-se como autossuficiente na maior parte dos produtos, figurando nas estatísticas referentes ao ano de 2009 como o 20 país que mais exportava alimentos no mundo. O PIB agrícola cresceu em média $10 \%$ desde a década de 1970 (SCHLESINGER, 2010).

Esse "progresso" não produziu apenas coisas positivas, infelizmente. Problemas surgiram, como êxodo rural, expulsão de posseiros, destruição da natureza, alteração da vida de diversas comunidades indígenas e, paralelo a isso, houve uma crescente onda de favelização de áreas urbanas próximas das terras tornadas agricultáveis. Estas são questões que não podem ser negadas e nem esquecidas pela sociedade. Precisamos assumir que tais problemas permanecem e devem ser, o quanto antes, solucionados da forma mais ampla e sólida.

Sendo assim, e pensamos ter externado isso no decorrer deste artigo por meio da problematização de diversas fontes, o Brasil precisa repensar, urgentemente, a política de ocupação agrícola do oeste brasileiro (e das terras do país como um todo), pois embora não faltem terras propícias à produção de alimentos, geração de riquezas e divisas que beneficiam diversos segmentos da sociedade nacional e internacional - e que, portanto, hoje não são mais vistas como estéreis -, a produção realizada pelos mais diversos trabalhadores sobre estas terras ainda é muito "estéril" para muitos dos brasileiros, pois mesmo sendo autossuficiente na produção alimentar, milhões de brasileiros deparam-se cotidianamente com a fome, e aqui parece redundância, justamente pela falta de alimento, algo que no Brasil - torna-se válido enfatizar - é o que cada vez se produz em maior quantidade e, também, em melhor qualidade.

Ademais, a luta pela terra ocorre com muita intensidade e vitima inúmeras pessoas. E num país como o nosso, dito de "dimensões continentais", é pouco aceitável e vergonhoso haver luta pela terra, assim pensamos, tendo em vista que terra é o que mais há neste "Brasil sem fim". 
Poderíamos entrar em conflito por qualquer outro motivo, mas não por terra, uma vez que, no Brasil, terra é o que não falta, pelo menos não quando comparamos a quantidade e a qualidade das terras existentes no Brasil e as existentes em outras nações do mundo.

\section{NOTAS}

${ }^{1}$ Aqui são necessárias, pelo menos, duas observações. Uma refere-se à afirmação da região em estudo ser a "a última fronteira agricultável do globo", pois este termo que não procede em análise pormenorizada. Contudo, a expressão foi e é utilizada em larga medida por inúmeros meios de comunicação e por variados sujeitos, já tendo se tornado lugar-comum em muitos segmentos da sociedade, e é neste sentido entendemos que ela faz parte da realidade social e não pode ser desconsiderada justamente em análises acadêmicas. E a outra observação versa sobre o termo "oeste" como um espaço que não possui um início e nem um fim, e sendo assim usa-se, no título deste artigo (e que poderíamos entendê-lo como demasiado genérico), a palavra Brasil, pois especificar o "oeste" como sendo uma área em particular do território brasileiro, ou delimitá-lo como uma porção específica de alguma unidade federativa, por mais que se focalize aqui a área dos atuais Estados de Mato Grosso e, mais ainda, de Mato Grosso do Sul, acarreta, assim pensamos, problemas mais expressivos do que não definir com exatidão em que local temos o início e em que linha visualizamos o término do oeste brasileiro, já que cada fonte indica um ou mais pontos para problematizarmos o oeste, e é ao considerar esta pluralidade de concepções que se pode pensar o chamado oeste brasileiro.

${ }^{2}$ As quatro últimas expressões - quais sejam: Hinterlândia Brasileira, Grande Estado do Oeste Brasileiro, Sibéria Brasileira e Brasil Central - constam, respectivamente, nas seguintes obras: Rondon (1934, p. 82-83), Corrêa (1940), Steinen (1942, p. 37) e Monbeig (1958, p. 70).

${ }^{3}$ Sobre este tratado de paz e amizade, que foi assinado pelo Barão de Cotegipe e por Carlos Loizaga em janeiro de 1872 na cidade de Assunção, ver a publicação intitulada Negociações com o Paraguay (1872, p. 37-38).

4 O surgimento do povoado de Campo Grande, atual capital política e administrativa do Estado de Mato Grosso do Sul (MS), é fruto, em certa medida, desta ação. 
${ }^{5}$ As terras litigiosas compreendiam aproximadamente $20-25 \%$ do território do sul de Mato Grosso, atual Estado de Mato Grosso do Sul. Consultando alguns escritos paraguaios, como o de Queirolo (1969), vê-se que o Tratado de Paz foi, na verdade, muito mais uma ação imperialista do Brasil do que, propriamente, um tratado. Em partes desta região - fronteira do Brasil com o Paraguai, sobretudo nas áreas de fronteira seca - ainda não se tem clareza do que é ser brasileiro e do que é ser paraguaio, e para muitos dos que ali residem isso pouco importa, exceto quanto $o$ assunto diz respeito à legislação. Segundo dados divulgados por Sodré (1941, p. 105), cerca de $89 \%$ da população residente na cidade de Porto Murtinho, antes da década de 1940, era composta por paraguaios. A quantidade de indígenas nesta região também era e ainda o é bastante expressiva. Sendo assim, a fronteira existente é muito mais a construída pelo saber cartográfico do que propriamente a materializada pelas relações sociais e econômicas. Na prática, a delimitação das fronteiras em benefício do Brasil foi possível devido à existência das atividades econômicas da erva-mate e da pecuária, pois ambas ocuparam efetivamente as terras antes litigiosas, tornando-as brasileiras. Ainda no tempo da Monarquia, mas em especial a partir de 1889, com o advento da República, a região sul de Mato Grosso passou a ser vista como um território que carecia da presença do elemento nacional brasileiro para brecar a presença do elemento estrangeiro - entenda-se $o$ paraguaio - haja visto que muitos paraguaios consideravam parte do sul de Mato Grosso como uma terra paraguaia. Portanto, havia constante preocupação de que parte do sul de Mato Grosso deixasse de ser terra brasileira.

"A ideia dos "espaços vazios" foi questionada por análises acadêmicas. Alcir Lenharo (1985) mostrou em seu estudo que não havia propriamente terras "sem donos", "espaços vazios" e "vazios territoriais e populacionais" no oeste do Brasil, pois os indígenas nunca se fizeram ausentes deste território. Estudos mais recentes, como o de Lúcia Salsa Corrêa (1999, p. 92), também confirmaram e ampliaram esta análise. "Na Historiografia tradicional sobre a região matogrossense foi bastante comum o uso dos conceitos desbravamento e vazios territoriais e populacionais, com o intuito de justificar o processo efetivo de ocupação do sertão que ocorreu nesse período. A idéia de um deserto de homens difundida por CORRÊA FILHO, menospreza o papel desempenhado pelas comunidades indígenas e pelas tentativas anteriores de fixação de espanhóis, sertanistas do século XVI e XVII e jesuítas, das quais restaram apenas vestígios após as investidas dos bandeirantes paulistas." Corrêa citou as seguintes obras de Virgílio Corrêa Filho: Ervais do Brasil e ervateiros, Fazendas de gado no Pantanal Mato-Grossense, História de Mato Grosso, Notas á margem, Pantanais MatoGrossenses e A proposito do boi pantaneiro.

${ }^{7}$ O fato é verídico. Em 1975, época da regularização das viagens rodoviárias da 
Região Sul para a Centro-Oeste ainda eram registrados casos de sumiço de pessoas durante o trajeto. Segundo o motorista Francisco Manique, que fazia a linha Cuiabá-Porto Velho, ocorriam paradas forçadas devido as condições do tempo e da estrada. No "trecho entre Ouro Verde e Vilhena, ele constatou, quando se preparava para reiniciar a viagem, que estava faltando um passageiro. "Saímos todos a procurá-lo no meio do barro", conta. "Encontramos o cadáver na floresta, estraçalhado por uma onça." (KUCK, 1984, p. 91).

${ }^{8} \mathrm{O}$ termo Mato Grosso Uno designa a região compreendida pelos atuais Estados de Mato Grosso (MT) e de Mato Grosso do Sul (MS) antes de 1977, ano da divisão de Mato Grosso Uno e da consequente criação de MS. A porção norte permaneceu com a denominação Estado de Mato Grosso.

${ }^{9}$ Nos anos 40 do século XX, Vargas empreendeu uma política de colonização que ficou conhecida como Marcha para o Oeste e, por meio dela, criou colônias agrícolas no norte do Paraná, em Goiás e no sul de Mato Grosso (região hoje chamada de Grande Dourados, que engloba mais de 10 municipalidades e fica no centro-sul de Mato Grosso do Sul). Muitas das terras consideradas como "espaços vazios" eram, na realidade, territórios de comunidades indígenas. Os conflitos entre "homens brancos" e "indígenas" foram intensificados e, hoje, ainda não estão resolvidos. Para uma análise mais detalhada desta questão, ver Pereira (2006).

${ }^{10}$ É importante mencionar que a sociedade pastoril foi extremamente útil para consolidar a posse das terras oestinas como brasileiras nas primeiras décadas do século XIX, porém, tempos depois, essa mesma cultura pastoril, inicialmente concebida como povoadora, passou a ser vista como um empecilho ao adensamento populacional desta mesma região, bem como ao desenvolvimento agrícola. Não se trata aqui, em absoluto, de desconsiderar as políticas empreendidas na Era Vargas e as ações realizadas posteriormente, em especial nos anos das décadas de 1950 a 1970, mais especificamente durante da Ditadura CivilMilitar pós-1964. Contudo, procurou-se neste escrito enfatizar outras concepções a respeito da terra no oeste do Brasil, dando relevo para materiais que, por vezes, não são considerados com tanta frequência pela historiografia brasileira, tanto a produzida em outros períodos como a contemporânea.

${ }^{11}$ A outra parte das terras era utilizada pela Companhia Matte Larangeira. Havia também as terras existentes nos pantanais, porém não eram propícias para plantios agrícolas, sobretudo por causa dos períodos de alagamentos, que são naturais em áreas de pantanais. A Companhia Matte Larangeira era uma empresa que atuava no extremo sul do Estado de Mato Grosso, localizando-se geograficamente entre os rios Paraná e Paraguai. Foi criada oficialmente em 1891, 
mas desde 1882 já eram desenvolvidas atividades. O fechamento da empresa se deu em 1947. A principal matéria-prima era a erva-mate, planta nativa da região. A maior parte da produção ia, via rio Paraguai, para a Argentina. $O$ trabalho era feito por cerca de 3 mil trabalhadores, muitos dos quais indígenas e paraguaios. 0 regime de trabalho era de semi-escravidão. A Cia. Matte Larangeira chegou a ter 5 milhões de hectares, a maioria proveniente de terras devolutas. Sobretudo nas décadas de 1980 e de 1990 foram elaborados alguns dos primeiros trabalhos acadêmicos que se detiveram em analisar aspectos desta Cia. Dentre os trabalhos realizados convém destacar os seguintes escritos: Weingärtner (1995), Arruda (1997), Corrêa (1999) e Bianchini (2000).

${ }^{12}$ Esta situação - fretamento de veículos para "exportação" de migrantes pobres foi noticiada em várias edições do periódico Correio do Estado no decorrer das décadas de 1960-70. Para outros detalhes sobre esta problemática, ver Moro (2009).

${ }^{13}$ Importante referenciar que determinados materiais mencionaram o grão da soja como sendo "soja do Japão". Consta em obra publicada em 1899 que a "cultura da soja" era "de grande utilidade, ao mesmo tempo que" era "rendosa; ela constitui uma excelente alimentação para a gente e também para os animais. Come-se o grão seco, ensopado ou cozido, fazendo-se dele, depois de seco e moído, magnífico pão. Os japoneses fazem da soja diversos alimentos. É, sobretudo, recomendada para uso dos diabéticos. Quer terreno profundamente lavrado: resiste aos parasitas animais e vegetais e a seca, podendo, portanto, desistir de irrigação. Semeia-se pelo processo de qualquer ervilha. Sua cultura é muito recomendada." GARCIA, Nogueira \& Cia., São Paulo. Manual do agricultor e Catalogo descriptivo da Loja e Chacara do Japão. São Paulo, 1899, p. 165-166.

${ }^{14} \mathrm{O}$ título do artigo de Amaral (1959) faz uma crítica à política econômica dos EUA, pois queriam que o mundo deixasse de consumir grãos, como o feijão, e proteína animal da carne bovina e passasse a se alimentar da soja produzida nesta nação. No entanto, com a venda da soja, os norte-americanos queriam, em troca, justamente carne e outros gêneros alimentícios que diziam para as outras nações não consumirem. Para Amaral, essa era uma forma de imperialismo que o Brasil não podia aceitar.

\section{REFERÊNCIAS}

ALMEIDA, Fernando F. M. de. A serra de Maracajú - a paisagem e o homem. Boletim da Associação dos Geógrafos Brasileiros, São Paulo, 
Indústria Gráfica José Magalhães Ltda., ano IV, n. 5, p. 60-78, nov. 1944.

AMARAL, F. Pompêo do. Soja - instrumento do imperialismo. Revista Brasiliense, São Paulo, n. 26, p. 42-58, nov./dez. 1959.

AMARAL, Luiz. A mais linda viagem: um "raid" de vinte mil kilometros pelo interior brasileiro. São Paulo/Cayeiras/Rio de Janeiro: Melhoramentos de São Paulo, 1927.

ARRUDA, Gilmar. Frutos da terra: os trabalhadores da Matte Larangeira. Londrina: UEL, 1997.

BARROS, Carlos Vandoni de. Em defesa do rio esquecido (Paraná). Rio de Janeiro: Câmara Federal, 1950.

BIANCHINI, Odaléa da Conceição Deniz. A Companhia Matte Larangeira e a ocupação da terra do sul de Mato Grosso (1880-1940). Campo Grande: UFMS, 2000.

BECK, Mario Lima. Nova querencia. Chronica das emigrações riograndenses para Matto Grosso. Porto Alegre: Selbach, 1935.

COMISSÃO INTERESTADUAL DA BACIA PARANÁ-URUGUAI. Condições geográficas e aspectos geoeconômicos da Bacia Paraná-Uruguai. São Paulo: Associação dos Geógrafos Brasileiros, 1955, v. 1.

CAMPOS, Fausto Vieira de. Retrato de Mato Grosso. São Paulo: [s.n.], 1955.

CORRÊA, Francisco de Aquino. Terra natal: versos a Matto-Grosso, o grande Estado do oeste brasileiro. Rio de Janeiro: Imprensa Nacional, 1940.

CORRÊA, Lúcia Salsa. História e fronteira. O sul de Mato Grosso (18701920). Campo Grande: UCDB, 1999.

CORRÊA, Valmir Batista. Fronteira oeste. Campo Grande: UFMS, 1999.

EMBRAPA. A soja no Brasil. Disponível em: <http://www.cnpso.embrapa.br/producaosoja/SojanoBrasil.htm>. Acesso em: 10 maio 2010.

GOES FILHO, Synesio Sampaio. Navegantes, bandeirantes, diplomatas: um ensaio sobre a formação das fronteiras no Brasil. São Paulo: Martins Fontes, 1999. 
KUCK, Cláudio. O Oeste mais perto. Revista Veja, São Paulo, p. 88-92, 19 set. 1984.

LENHARO, Alcir. Colonização e trabalho no Brasil: Amazônia, Nordeste, Centro-Oeste: anos 30. Campinas: UNICAMP, 1985.

LIMA, Archimedes. Problemas matogrossenses. Cuiabá: Imprensa Oficial, 1941.

MARQUES, A. Matto Grosso: seus recursos naturaes, seu futuro economico. Rio de Janeiro: Americana, 1923.

MONBEIG, Pierre. O Brasil. 2. ed. São Paulo: Difusão Européia do Livro, 1958.

MORO, Nataniél Dal. A constituição de uma elite rural: o caso dos sojicultores em Mato Grosso do Sul (décadas de 1970-80). In: Anais do 39o Encontro Nacional de Estudos Rurais e Urbanos, CERU/USP, São Paulo, p. 114, 2012.

- Modernização urbano-citadina e representações sobre os trabalhadores na cidade de Campo Grande (décadas de 1960-70). 2007. 365 f. Dissertação (Mestrado em História Social) - Programa de Estudos PósGraduados em História, Pontifícia Universidade Católica de São Paulo (PUCSP), São Paulo, 2007.

- Representações da elite sobre o "povo comum" na cidade de Campo Grande (décadas de 1960-70). Fronteiras: Revista do Programa de Pós-Graduação - Mestrado em História da UFGD, Dourados, v. 11, n. 20, p. 123-149, jul./dez. 2009.

NEGOCIAÇÕES COM O PARAGUAY. Rio de Janeiro: Typographia Universal de Laemmert, 1872.

PEREIRA, Levi Marques. Assentamentos e formas organizacionais dos Kaiowá atuais: o caso dos "índios de Corredor". Revista Tellus, Campo Grande, UCDB, ano 6, n. 10, p. 69-81, abr. 2006.

QUEIROLO, Víctor Ayala. Historia de la cultura en el Paraguay. Asunción: Salesiana, 1969.

RONDON, Frederico. Colonização nacional, o magno problema brasileiro. 
Boletim geográfico, Rio de Janeiro, SGEF, ano IV, n. 46, p. 1331-1341, jan. 1947. . Pelo Brasil Central. São Paulo: Nacional, 1934.

SCHLESINGER, Sergio. A soja no Brasil. Disponível em: <http://www.comova.org.br/pdf/observandosoja/12-A-soja-no-Brasil.pdf>. Acesso em: 10 maio 2010.

SILVA, José Graziano da. A modernização dolorosa: estrutura agrária, fronteira agrícola e trabalhadores rurais no Brasil. Rio de Janeiro: Zahar, 1982.

SODRÉ, Nelson Werneck. Oeste: ensaio sobre a grande propriedade pastoril. Rio de Janeiro: José Olympio, 1941.

STEINEN, Karl von den. O Brasil Central: expedição em 1884 para a exploração do rio Xingu. São Paulo: Nacional, 1942.

WEINGÄRTNER, Alisolete Antonia dos Santos. Movimento divisionista em Mato Grosso do Sul (1889-1930). Porto Alegre: Edições EST, 1995. 